\title{
High-Resolution Prediction for the Amount of Airborne Sea Salt by Multi-Scale Weather Simulation ${ }^{* 1}$
}

\author{
Ryo Onishi ${ }^{1,2, * 2}$, Keigo Matsuda ${ }^{2}$, Hitoshi Suto ${ }^{3}$, Yasuo Hattori ${ }^{3}$, Hiromaru Hirakuchi ${ }^{3}$, \\ Shigeyuki Matsunami ${ }^{4}$, Shinjiro Yagyu ${ }^{5}$, Tadashi Shinohara ${ }^{6}$ and Hideki Katayama ${ }^{6}$ \\ ${ }^{1}$ Global Scientific Information, Tokyo Institute of Technology, Tokyo 152-8550, Japan \\ ${ }^{2}$ Research Institute for Value-Added-Information Generation, Japan Agency for Marine-Earth Science and Technology, \\ Yokohama 236-0001, Japan \\ ${ }^{3}$ Civil Engineering Research Laboratory, Central Research Institute of Electric Power Industry, Abiko 270-1194, Japan \\ ${ }^{4}$ Research and Services Division of Materials Data and Integrated System, National Institute for Materials Science, \\ Tsukuba 305-0044, Japan \\ ${ }^{5}$ Research Center for Functional Materials, National Institute for Materials Science, Tsukuba 305-0044, Japan \\ ${ }^{6}$ Corrosion Property Group, Research Center for Structural Materials, National Institute for Materials Science, \\ Tsukuba 305-0047, Japan
}

A new methodology to calculate and visualize the amount of airborne sea salt with a $100 \mathrm{~m}$ mesh resolution in high definition has been proposed in this study. A transport calculation module for airborne sea salt is implemented to the atmospheric component of the multi-scale atmosphere-ocean coupled model. The computational fluid dynamics model (NuWiCC-ST) results that can calculate the generation and transport of sea salt particles are incorporated to the transport calculation. The coupled methodology has been applied to create a corrosion environment map for Choshi City. The reliability of the developed method was confirmed by comparing airborne sea salt data measured using the dry gauze method with the calculated data. [doi:10.2320/matertrans.C-M2021848]

(Received June 28, 2020; Accepted December 9, 2020; Published November 25, 2021)

Keywords: atmospheric corrosion, sea salt particle, weather simulation, computational fluid dynamics, high-resolution corrosion map

\section{Introduction}

Japanese infrastructure is continuously aging. For example, there are approximately 720,000 road bridges in Japan, and by $202952 \%$ of these bridges will be over 50-years-old. The shortage of maintenance costs and the lack of human resources to inspect infrastructure is becoming increasingly critical. In addition, as the local governments manage approximately $70 \%$ of bridges in Japan, it is considered that the burden on bridge repairs will increase in most of the local governments.

Although airborne sea salt is one of the factors of corrosion of steels, it has currently not been possible to visually grasp the distribution of the actual amount of airborne sea salt on land. To maintain and manage a large number of bridges distributed over a wide area efficiently, the coastal municipalities have required a method to quantitatively and efficiently estimate a wide-area distribution of airborne sea salt over a long period with consideration of local topography.

One of the effective methods for estimating the amount of airborne sea salt is numerical analysis. The existing numerical analyses for airborne sea salt can be classified into four categories: (1) simplified method based on algebraic and ordinary differential equations, ${ }^{1,2)}$ (2) methodology based on engineering computational fluid dynamics (CFD) model, ${ }^{3-5}$ ) (3) methodology based on mesoscale weather model (MMM; mesoscale meteorology model), ${ }^{6,7)}$ and (4) methodology combining the above methods (2) and (3). ${ }^{8}$

\footnotetext{
${ }^{* 1}$ This Paper was Originally Published in Japanese in ZAIRYO-TOKANKYO 69 (2020) 169-174.

${ }^{* 2}$ Corresponding author, E-mail: onishi.ryo@gsic.titech.ac.jp
}

In this study, we have developed a new technique incorporating a high-resolution MMM with a CFD to obtain a high-definition corrosion map that enables the visualization of airborne sea salt. Specifically, we perform high-resolution downscale simulations of airborne sea salt using the multiscale atmosphere-ocean coupled model (MSSG; multi-scale simulator for the geoenvironment). ${ }^{9,10)}$ This is also incorporated with the transport simulation model of sea salt particles (NuWiCC-ST; numerical wind simulation code-customized edition for evaluation of sea salt transport). ${ }^{11)}$ The models are coupled offline through the vertical profiles of the amount of airborne sea salt. The lateral boundary conditions, depending on particle sizes, wind direction and speed, required for the MSSG simulations, are obtained from the NuWiCC-ST simulations. While the above-described Method (4) utilizes MMM data to calculate the amount of airborne sea salt by CFD, our proposed method can be defined as a derivative of Method (4) in terms of proposing a new coupling method between MMM and CFD. To confirm the reliability of this proposed method, we compare the amount of airborne sea salt collected by the dry gauze method in Choshi City (Chiba Prefecture, Japan) and the simulation results.

\section{Downscale Simulation Method for the Amount of Airborne Sea Salt}

\subsection{Lateral boundary conditions and offline coupling} scheme for the amount of airborne sea salt

This study proposes a high-resolution downscale simulation method in which MMM and CFD are coupled offline through lateral (side) boundary conditions of airborne sea 
salt concentrations. CFD obtains vertical profiles of airborne sea salt concentration in each particle size (3 ranks), wind direction (4 wind directions), and wind velocity (5 ranks), specifically, NuWiCC-ST ${ }^{11}$ ) with a $1 \mathrm{~km}$ horizontal resolution. They are then used for high-resolution MMM, specifically, MSSG with $100 \mathrm{~m}$ horizontal resolution as lateral boundary conditions. The NuWiCC-ST simulation can consider sea salt generation processes in detail, whereas the MSSG simulation can consider the sea salt transport process with higher resolution. The two simulations are performed separately and coupled offline.

Herein, we briefly discuss the validity of the present offline coupling. The air flows through the high-resolution simulation domain in time $T_{d} \sim L_{d} / \mathrm{U} 10$, where $L_{d}$ is the horizontal length of the high-resolution simulation domain, and $\mathrm{U} 10$ is the wind speed at $10 \mathrm{~m}$ height. The offline coupling can be justified if $T_{d}$ is sufficiently small compared with the fluctuating time scale $T_{S}$ of wind velocity and direction, i.e., if $T_{d} \ll T_{s}$. For example, the size of the MSSG high-resolution simulation domain in this study was approximately $20 \mathrm{~km}^{2}$ (see Section 2.3 ), and U10 is usually from several m/s to $10 \mathrm{~m} / \mathrm{s}$. Hence the time scale of $T_{d}$ was approximately $1 \mathrm{~h}$. In the coastal area, such as Choshi City targeted in this study, sea breeze dominates the local wind direction within a day, for which $T_{S}$ can be estimated from a few hours to half a day. As for mesoscale events involving frontal events, $T_{s}$ would be approximately a day. That is, the assumption of $T_{d} \ll T_{s}$ is justified reasonably. Notably, $T_{s}$ may be approximately an hour or less for some sudden local events. However, the total duration of such sudden change periods would not become significant for the discussion on, e.g., daily accumulation map of the amount of sea salt.

\subsection{Procedures for offline coupling through lateral boundary conditions for the amount of airborne sea salt}

The following steps show the procedures to couple the NuWiCC-ST's airborne sea salt results with the MSSG highresolution downscale simulations.

1. To perform the NuWiCC-ST for specific particle size (3 ranks), wind direction (4 wind directions), and wind velocity ( 5 ranks) for the target domain and to obtain vertical profiles of amount of sea salt at the domain's center.

2. To perform the MSSG high-resolution mesoscale weather simulation for the target domain without sea salt transport calculations and to extract a time-series of horizontal wind speed at $10 \mathrm{~m}$, i.e., U10 averaged over the representative area in the domain.

3. To create a time-series of vertical profiles of sea salt concentration at lateral boundaries (north, south, east, and west boundaries) for a simulation period according to the U10 time series data obtained in Procedure 2 from the set of NuWiCC-ST results obtained in Procedure 1. The concentration data for arbitrary wind speeds are obtained by linearly interpolating the data for the 5 wind ranks.

4. To perform the MSSG high-resolution simulation with the sea salt transport calculation using the lateral boundary conditions obtained in Procedure 3.

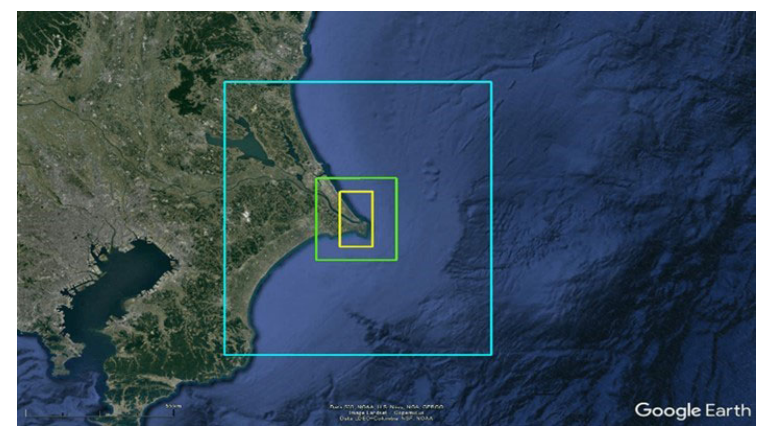

Fig. 1 Computational domains of the MSSG simulation for Choshi. Twoway coupled simulations for the three nested domains were conducted.

Table 1 Computational setting for the MSSG two-way nested simulation for the Choshi area.

\begin{tabular}{|c|c|c|c|}
\hline Nest level & 0 & 1 & 2 \\
\hline Center & $35.752148^{\circ} \mathrm{N}, 140.827321^{\circ} \mathrm{E}$ \\
\hline Number of horizontal grids & $120 \times 120$ & $120 \times 120$ & $145 \times 240$ \\
\hline Horizontal resolution & $1,000 \mathrm{~m}$ & $300 \mathrm{~m}$ & $100 \mathrm{~m}$ \\
\hline Domain height & \multicolumn{3}{|c|}{$40,000 \mathrm{~m}$} \\
\hline Number of vertical grids & \multicolumn{3}{|c|}{55} \\
\hline Vertical resolution & \multicolumn{3}{|c|}{$75 \mathrm{~m}$ (minimum) } \\
\hline
\end{tabular}

2.3 Examples of vertical profiles of the amount of airborne sea salt concentration at lateral boundaries for MSSG down-scale simulations

Figure 1 and Table 1 show the present MSSG simulation domain and settings (grid intervals and grid numbers) for the amount of airborne sea salt calculation for five days from July 1, 2017, at 00 UTC (Coordinated Universal Time) to July 6, 2017 , at 00 UTC. The center position of the domain was set at $35.752148^{\circ} \mathrm{N}$ and $140.827321^{\circ} \mathrm{E}$, targeting the Choshi area with three layers of nested domains.

The outermost domain, the nesting level 0, was a rectangular region of $120 \mathrm{~km}^{2}$ with a horizontal grid spacing of $1,000 \mathrm{~m}$. The inner domain with the nesting level 1 was a region of $36 \mathrm{~km}^{2}$ with horizontal grid spacing of $300 \mathrm{~m}$. The innermost domain with the nesting level 2 is a rectangular region of $14.5 \mathrm{~km} \times 24 \mathrm{~km}$ with a horizontal grid spacing of $100 \mathrm{~m}$. The number of vertical layers was the same for all the three levels, and a total of 55 layers were used. The lowermost layer thickness of the vertical grid was $75 \mathrm{~m}$, and the grid width increases linearly with increased height. The height of the computational domain was $40,000 \mathrm{~m}$. Additional information on the MSSG high-resolution weather simulation is described in the next subsection.

The calculation of the amount of airborne sea salt was carried out for the innermost domain using the nesting level 2. The time-series data for U10 in the nesting level 2 area is obtained in Procedure 2. In this study, the spatial mean value of $U 10$ at $10 \times 10$ grid points over the southeast sea in the innermost domain was obtained. The time-series data was then used for preparing the lateral vertical profiles of airborne sea salt concentrations. For example, the time-series 


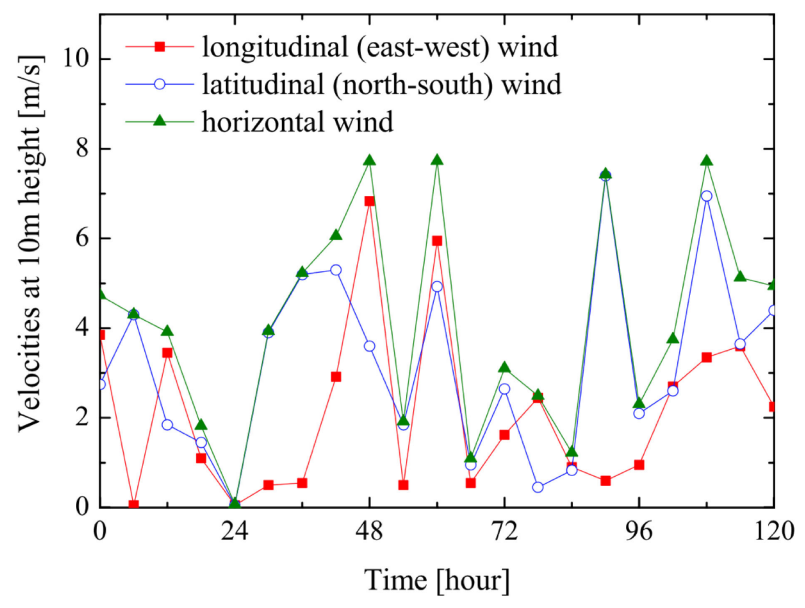

Fig. 2 Time-series of the wind velocities at $10 \mathrm{~m}$ height averaged over $10 \times 10$ grid points in the southeast part of the highest-resolution domain, denoted by the yellow rectangular in Fig. 1. The red line indicates the meridional (east-west) velocity, the blue line indicates the latitudinal (north-south) velocity, and the green line indicates the horizontal velocity.
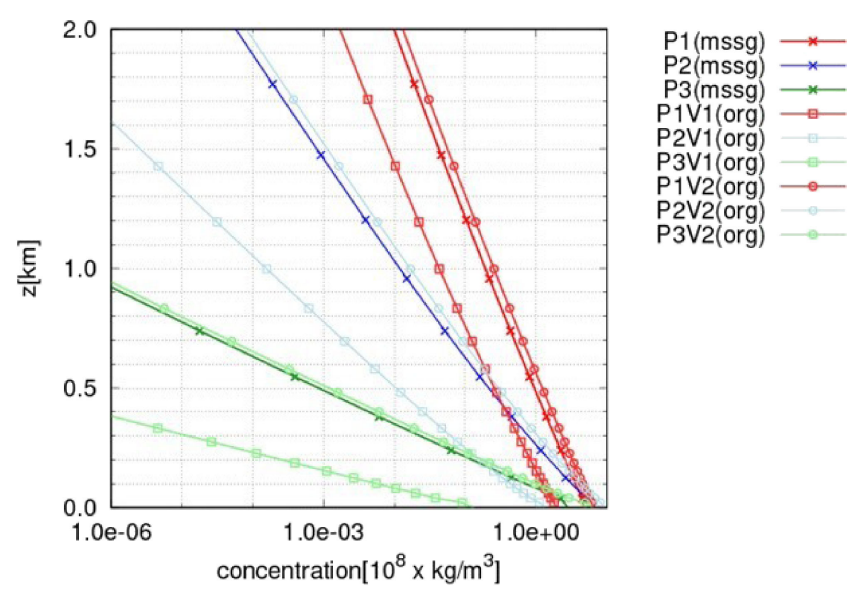

Fig. 3 Vertical distributions of the seasalt concentration, Pp(mssg) ( $p$ is one of the particle classes; 1,2 , or 3 ), for the lateral boundaries of the MSSG simulation at 9 am (JST), July 3, 2017 together with the vertical distributions from the NuWiCC-ST simulation. For example, PpV1 (org) of the wind velocity class $1(4 \mathrm{~m} / \mathrm{s})$ and the data PpV2 (org) of the wind velocity class $2(8 \mathrm{~m} / \mathrm{s})$ were used to generate the data $P$ p for the wind of $6.8 \mathrm{~m} / \mathrm{s}$ at the corresponding period.

data of the obtained U10 and its meridional (east-west) and latitudinal (north-south) velocity are shown in Fig. 2.

Figure 3 shows the vertical profiles of the airborne sea salt concentration at lateral boundaries for the MSSG simulation at 9:00 on July 3, 2017 (JST: Japan Standard Time), obtained in Procedure 3. The eastward wind speed was $6.8[\mathrm{~m} / \mathrm{s}]$. For preparing the east lateral boundary data (labeled "mssg" in the figure) for the MSSG simulation, the airborne sea salt concentration was linearly interpolated between the values for an eastward wind speed of $4 \mathrm{~m} / \mathrm{s}$ and those for $8 \mathrm{~m} / \mathrm{s}$ (labeled "org" in the figure) from NuWiCC-ST simulations at a horizontal resolution of $1 \mathrm{~km}$ for the Choshi area. In easterly wind conditions, the east lateral boundary is an inlet boundary, and the west one an outlet boundary. Instead of using a free outlet condition, this study used the same condition for the inlet and outlet boundaries. Moreover, the

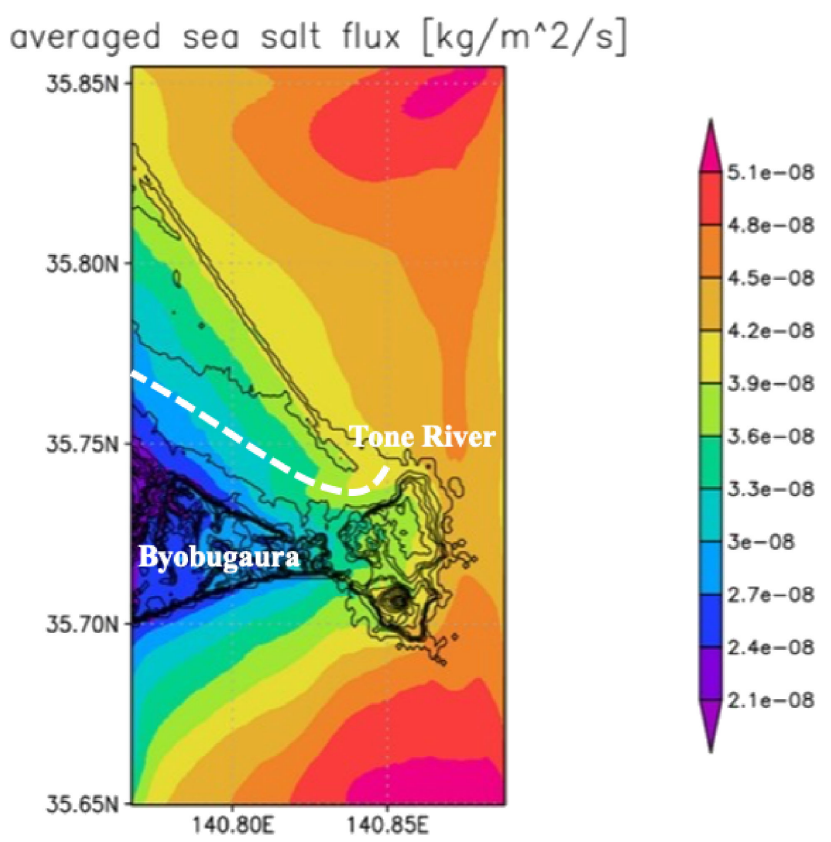

Fig. 4 A 100 m-resolution map of seasalt concentration in the lowest layer $(z=37.5 \mathrm{~m})$. Mean values for 5 days (July 1-6, 2017) are shaded in a rainbow color. The contour shows the topography used for the calculation.

same algorithm was used to prepare the north and south lateral boundary data. This simple treatment would work reasonably for over uniform terrains, e.g., when all the domain is sea or land, but may fail for nonuniform terrains. For example, the amount of airborne sea salt becomes extremely small under the land breeze compared to those under the sea breeze. Therefore, in the present calculations targeting the Choshi region, the amount of airborne sea salt over land at the west lateral boundary was set to 0 for land breeze cases (i.e., westerly wind).

Using the offline coupled scheme, the lateral boundary data of the airborne sea salt concentration was generated for every $3 \mathrm{~h}$. The generated three-hourly data were linearly interpolated in time using the MSSG high-resolution simulations, usually with time intervals of a few seconds.

\subsection{High-resolution simulation for the amount of air- borne sea salt}

The amount of airborne sea salt of $100 \mathrm{~m}$ horizontal resolution was calculated using the lateral boundary data for the Choshi region. The target period was five days from 00 UTC on July 1, 2017, to 00 UTC on July 6, 2017. Figure 4 shows the horizontal distribution of the airborne sea salt flux at the lowest point (altitude: $37.5 \mathrm{~m}$ ) averaged over five days. The distribution indicates that airborne sea salt intrudes inland through the Tone river mouth. This phenomenon is successfully reproduced by calculating the Tone River's estuarine area, whose width is approximately $1 \mathrm{~km}$ near the mouth, with high enough resolution. It is also shown that the sea cliff of Byobugaura at an altitude of approximately $50 \mathrm{~m}$, and extending approximately $10 \mathrm{~km}$ in the east-west direction of the south coast, blocks the airborne sea salt intrusion on the southerly wind. Previously, Matsunami et al. ${ }^{12)}$ obtained the analysis value for the amount of airborne sea salt (annual mean value) in the area 


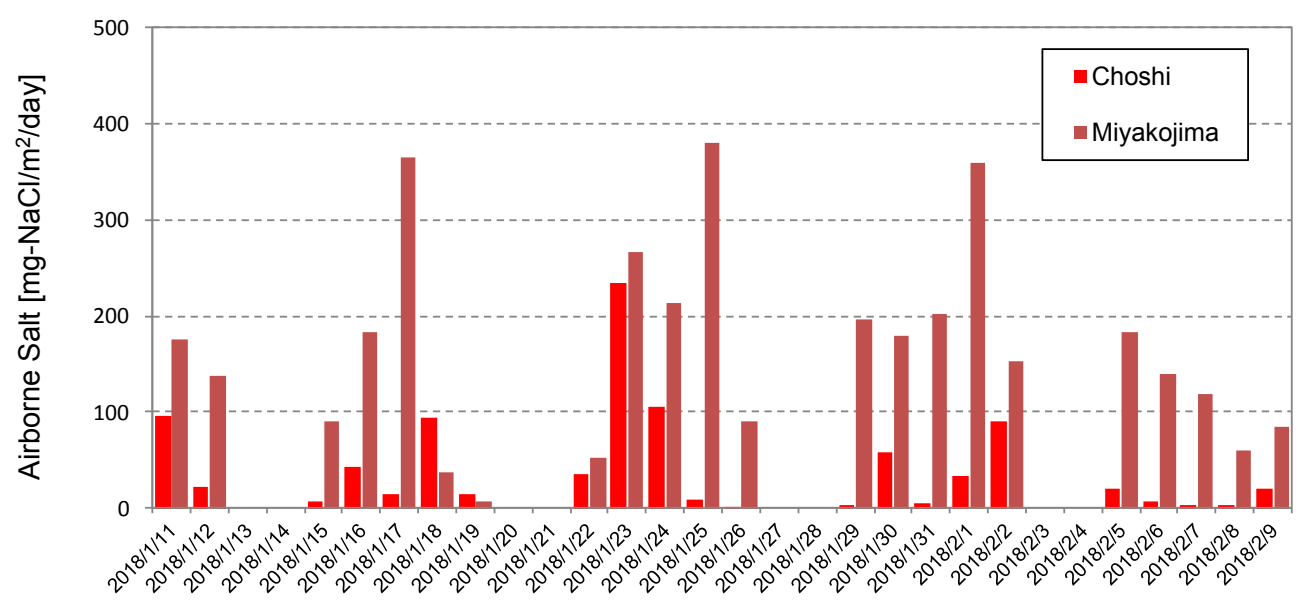

Fig. 5 Daily changes in airborne sea salts at the JWTC Choshi and Miyakojima sites (Jan. 10-Feb. 9, 2018).

of Choshi City calculated by NuWiCC-ST from the tertiary region mesh (approximately $1 \mathrm{~km}$ unit) to obtain the equal airborne sea salt dose. From this, they examined the effect of the proper topography of Choshi on the amount of airborne sea salt and acquired knowledge, such as the distance from shore and the topography of airborne sea salt. The current MSSG high-resolution simulations successfully reproduced the effect of inland inflow of airborne sea salt along the Tone River with a wide estuary area and the effect of microtopography of a coastal cliff in the Choshi area. The simulations also succeeded in obtaining the airborne sea salt dose with clearer correspondence to microtopography than previous studies.

\section{Verification of MSSG High-Resolution for the Amount of Airborne Sea Salt Simulation}

\subsection{Verification method}

In the case of the corrosion test, such as an exposure test, the amount of airborne sea salt and meteorological data are measured and tabulated in both monthly and annual scales. It is difficult for such in-situ measurement to observe the spatial distribution of airborne sea salt or the flux of airborne sea salt particles. Therefore, the amount of airborne sea salt collected by the JIS method (JIS Z 2382: dry gauze method) or the ISO method (ISO 9225: wet candle method) is generally used as an index for the corrosive environment. Although the collection of airborne sea salt is mainly carried out by the JIS method in Japan, there has not been much discussion on the correlation between the flux of airborne sea salt (calculated value) and the amount of sea salt collected by the JIS method. ${ }^{13)}$

Verification of the MSSG calculation was performed by comparing the cumulative value of the daily airborne sea salt obtained from the flux with that collected by the dry gauze method, considering the number of resources required for the calculation. The daily amount of airborne sea salt is measured by the dry gauze method between January 10 and February 9 , 2018, at two sites of the Japan Weathering Test Center (JWTC): Choshi exposure test site in Choshi City (Choshi Site) and Miyakojima exposure test site in Miyakojima City (Miyakojima Site).
Table 2 Measurement of airborne sea salt and capture rate at the JWTC Choshi and Miyakojima sites.

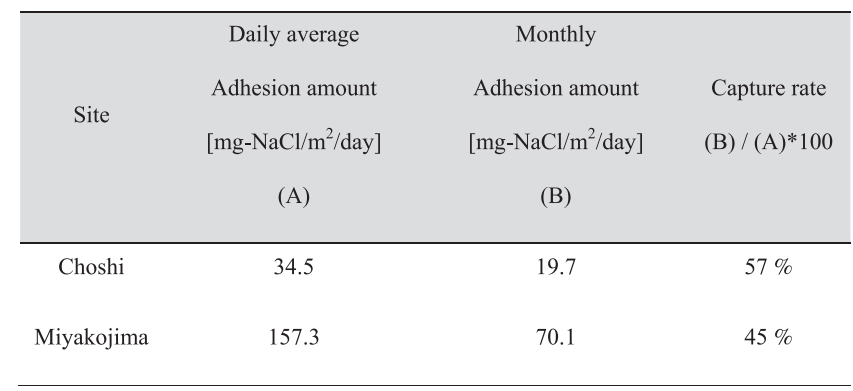

\subsection{Exposure test}

The amount of airborne sea salt at each exposed area was measured by the dry gauze method according to JIS Z 2382. Dry gauze was installed in a well-ventilated structure to prevent the effects of rain. Two dry gauze were used in this study, the first to measure the daily amount of airborne sea salt, and the second to measure the amount of airborne sea salt for 30 days. As the dry gauze was not replaced on the weekend, the amount of airborne sea salt measured with the dry gauze set on Friday equals the sum of the amount on the weekend. Therefore, the comparison with the analysis value in MSSG was performed with the daily data from Tuesday to Friday. Moreover, as the MSSG calculation was a trial targeting only Choshi City, the actual values were referenced to the JWTC Choshi data.

Figure 5 shows the daily changes in the amount of airborne sea salt for the JWTC in Choshi and Miyakojima. The amount of airborne sea salt fluctuates greatly every day, and the amount of airborne sea salt on Miyakojima tends to be higher than that on Choshi. The average value of the amount of airborne sea salt (daily average) for these 30 days was $34.5 \mathrm{mmd}$ for Choshi and $157.3 \mathrm{mmd}$ for Miyakojima. Miyakojima was approximately four times more than Choshi, as shown in Table 2. On the other hand, the amount of airborne sea salt (monthly average) measured with the dry gauze exposed for one month was 19.7 and $70.1 \mathrm{mmd}$ for Choshi and Miyakojima. These averages indicate that the monthly collection rate with dry gauze is approximately $50 \%$. 
Therefore, although the amount of airborne sea salt measured by the dry gauze method is the value collected for one month, it also includes the effect of separation and desorption due to wind and other factors. Such meteorological variables become different time to time. It is not justified to evaluate the corrosive environment only by the total amount of collected airborne sea salt for a long period. Here we compare the daily amount of deposited sea salt with numerical results. The amount of airborne sea salt flux (AASS) and the amount of deposited sea salt (ADSS) can be expressed.

$$
\begin{aligned}
& \text { AASS }=\text { atmospheric salt density } \times \text { wind speed } \\
& \text { ADSS }=\text { AASS } \times \text { coefficient }+\mathrm{E}
\end{aligned}
$$

Here, $\mathrm{E}$ is an observation error and includes external factors such as washing away deposited sea salt due to rainfall at a part exposed to rain, e.g., the surface of a bridge. Although the degree of adsorption and desorption of sea salt is considered largely dependent on meteorological factors and regions, the coefficient (collection rate in gauze) in this study can be regarded as almost constant from the measurements at the two sites.

\subsection{Comparison of observed and calculated values}

Figure 6 shows the relationship between the daily amount of deposited sea salt at the JWTC Choshi site during the first week of the exposure test (January 11 to January 18, 2018) and the daily airborne sea salt flux calculated at a horizontal resolution of $100 \mathrm{~m}$ by MSSG. The daily change in the measured values is in good agreement with those of the calculated values. The horizontal axis and vertical axis in Fig. 6(b) correspond to the measured value and value calculated by MSSG, respectively. The coefficient was 104.54 due to the approximation of the data by the relationship between single phases shown in eq. (2). As the correlation coefficient is more than 0.8 , it can be concluded that MSSG can predict the local amount of airborne sea salt with high accuracy. The reciprocal of the coefficient (0.0095) indicates the collection rate of airborne sea salt by the dry gauze method, which is in good agreement with the previously reported results. ${ }^{13)}$

This study calculated an average flux value at $100 \mathrm{~m}$ mesh, and confirmed that such a high-resolution meteorological calculation could reflect the observation sites microtopography. This study has targeted the open environment of the JWTC Choshi test site, which is surrounded by no micrometeorological obstacles (e.g., $1-10 \mathrm{~m}$ sized buildings and trees). It is well-known that the corrosion speed is sometimes affected strongly by $1-10 \mathrm{~m}$ sized obstacles. Recently, the large-eddy simulation becomes a promising tool to consider the effects of buildings on micrometeorology (i.e., street-scale weather) ${ }^{14,15)}$ It can also be used to examine the effects of tree crowns if the proper model such as Kanda and Hino ${ }^{16)}$ is implemented. The MSSG has a large-eddy simulation (LES) component that can consider the effects of building and tree crowns. ${ }^{17,18)}$ If this component is incorporated with the present method, it would become possible to make a precise comparison between calculated and measured values at the exact collection points, often among micrometeorological obstacles.
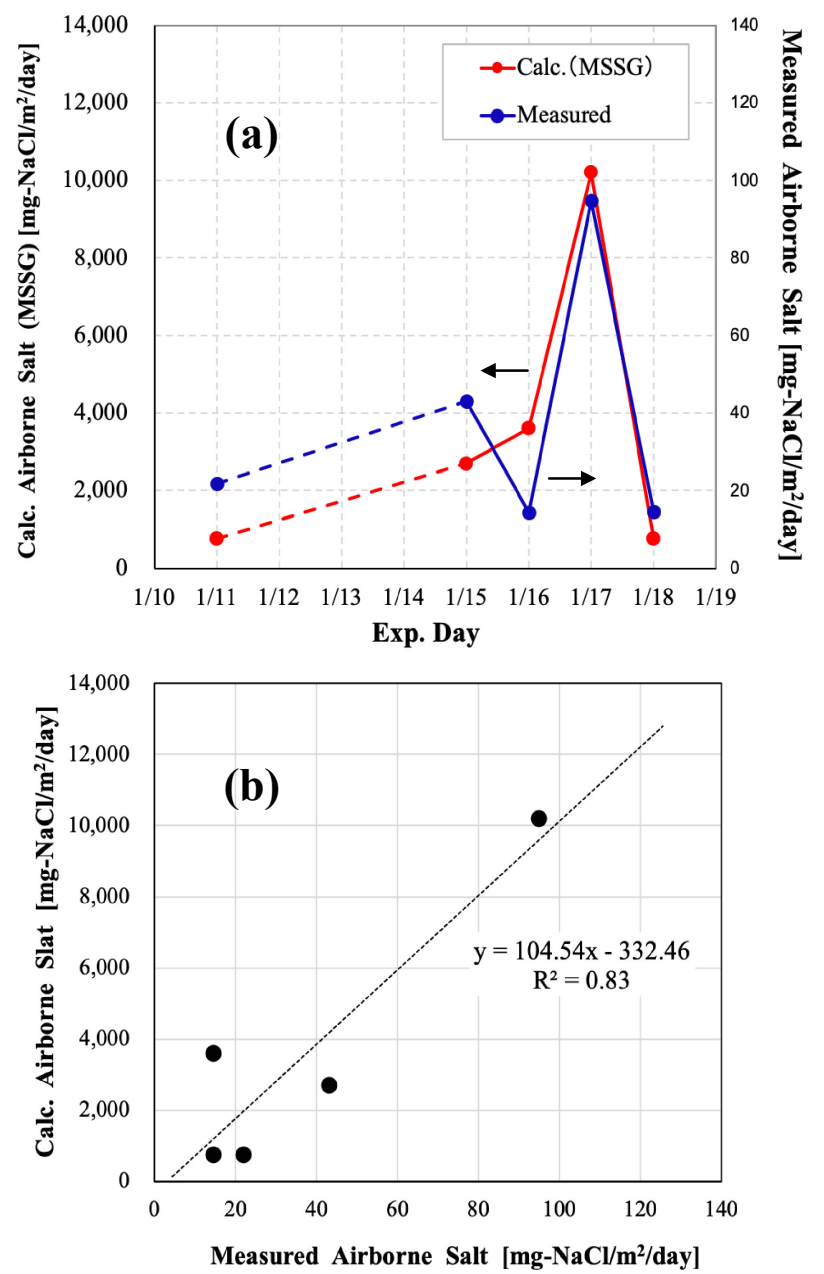

Fig. 6 (a) Calculated airborne sea salt by MSSG (Jan. 11-18, 2018) and measured airborne sea salt at the JWTC Choshi site. (b) Relationships between measured and calculated airborne sea salt.

\section{Conclusions}

We have developed a numerical analysis method in order to improve the prediction of the airborne sea salt flux by applying the high-resolution meteorological simulation method. This method can be used to create a highly precise corrosion environment map in approximately $100 \mathrm{~m}$ mesh using a multiscale atmosphere-ocean coupled model MSSG. Specifically, the distribution data of airborne sea salt particles for each particle size, wind direction, and wind speed calculated by the sea salt particle transport simulation model NuWiCC-ST was used as the boundary data for highresolution downscale calculation using MSSG. Herein, only the advection and subsidence of airborne sea salt were calculated without considering the local generation of sea salt particles in the high-resolution calculation region. Therefore, it is possible to consider the advection and diffusion of sea salt particles in the atmospheric boundary layer more precisely by examining the effects of microtopography and detailed land use by high-resolution meteorological calculations.

The amount of airborne sea salt with a $100 \mathrm{~m}$ mesh for the Choshi City by the proposed method was compared with the amount of deposited sea salt obtained by the dry gauze method at the JWTC Choshi exposure test site. It was 
confirmed that there is a high correlation between the calculation results and observation results. In addition, it was qualitatively clarified that, to reproduce the intrusion of sea salt particles to the land near the Tone River's mouth, the calculation with a high-resolution mesh of approximately $100 \mathrm{~m}$ is necessary.

MSSG has a building-resolving large-eddy simulation (LES) component that can consider the effects of buildings and tree crowns on micrometeorology. The introduction of the proposed method to that LES component of MSSG can estimate the distribution of airborne sea salt on the structural scale considering the distribution of micrometeorological factors. Such advancements would lead to a more precise understanding of the corrosive environment.

\section{Acknowledgement}

Part of the results of this study was supported by the NEDO program "Development of Infrastructure for Creating New Industrial Models Utilizing IoT". The large-scale numerical calculation was carried out using the Earth Simulator of the Japan Agency for Marine-Earth Science and Technology.

\section{REFERENCES}

1) S. Feliu, M. Morcillo and B. Chico: Corrosion 55 (1999) 883-891.

2) G.R. Meira, C. Andrade, C. Alonso, I.J. Padaratz and J.C. Borba: Corros. Sci. 50 (2008) 2724-2731.
3) Y. Kang, K. Noguchi, S. Okuda, N. Kurata, H. Shirato, T. Yagi, T. Morishita and Y. Tanaka: Proceedings of the 22nd National Symposium on Wind Engineering. JAWE (2012).

4) M. Obata, Y. Watanabe, G.T. Li and Y. Goto: Procedia Eng. 14 (2011) 1043-1050.

5) F. Yamada and T. Hosoyamada: Proceedings of the 7th Int. Conf. on Hydroscience and Engineering (2006).

6) N. Kihara, H. Hirakuchi, A. Takahashi, S. Ohara and S. Fujita: Proceedings of the 7th Asian Aerosol Conference, (2011).

7) S. Tsyro, W. Aas, J. Soares, M. Sofiev, H. Berge and G. Spindler: Atmos. Chem. Phys. 11 (2011) 10367-10388.

8) M. Obata, Y. Watanabe, G.T. Li and Y. Goto: Struct. Infrastruct. Eng. 10 (2014) 398-408.

9) K. Takahashi, R. Onishi, Y. Baba, S. Kida, K. Matsuda, K. Goto and H. Fuchigami: J. Phys.: Conf. Ser. 454 (2013) 012072.

10) R. Onishi and K. Takahashi: J. Atmos. Sci. 69 (2012) 1474-1497.

11) H. Suto, Y. Hattori, H. Harakuchi, N. Kihara and Y. Nakashiki: Struct. Infrastruct. Eng. 13 (2017) 1359-1371.

12) S. Matsunami, S. Yagyu, T. Shinohara, H. Katayama, H. Suto, Y. Hattori and H. Hirakuchi: J. Japan Soc. Civil Eng. Ser. A1 75 (2019) 141-160.

13) H. Suto, Y. Hattori, H. Hirakuchi and N. Kihara: CRIEPI Research Report, N15007 (2016).

14) N.H. Ahmad, A. Inagaki, M. Kanda, N. Onodera and T. Aoki: Boundary-Layer Meteorol. 163 (2017) 447-467.

15) B. Maronga, M. Gryschka, R. Heinze, F. Hoffmann, F. Kanani-Sühring, M. Keck, K. Ketelsen, M.O. Letzel, M. Sühring and S. Raasch: Geosci. Model Dev. 8 (2015) 2515-2551.

16) M. Kanda and M. Hino: Boundary-Layer Meteorol. 68 (1994) 237257.

17) K. Matsuda, R. Onishi and K. Takahashi: J. Wind Eng. Ind. Aerodyn. 173 (2018) 53-66.

18) R. Onishi, D. Sugiyama and K. Matsuda: SOLA 15 (2019) 178-182. 